\title{
Philosophical Relevance of a Rational - Empiricist's Epistemology for Education
}

\author{
Muhammad Inuwa Usman \\ Kebbi State University of Science and Technology, Aliero, Nigeria
}

\begin{abstract}
Empiricism has been established as a foundational approach to knowledge. This is based on the fact that empiricism focuses on the sources of knowledge rather than what is known. In assuming the modern day empiricism, we would want to know to what extent empiricism justifiably forms basis of knowledge and experience. This paper therefore, critically examined three basic concepts that are crucial to empirical discussions on education. These concepts are knowledge, experience and perception. The paper examines the foundational role of empiricism in these concepts. The emphasis is on the concept of experience and its importance in man's ability to learn and if necessary to teach. Such an examination into the nature of experience can be considered relevant to education in as much as it is linked with teaching and learning. The practice of education borders on these two activities. Our notion of relevance lies in our contention that education must focus on the content of knowledge which the learners acquire, how they acquire it, and as well, how to convert learning into useful action. The paper summed up its findings in some postulates reflecting the empirical nature of knowledge and has inevitably bind knowledge acquisition with experience. The focus is on rational dimension of experience in contradistinction to the sensual dimension that has been recognized by empirical thinkers over the year. This is because man needs to be rational in order to work meaningfully in the world. The paper is on both philosophy and education. On the philosophical note it has examined empiricism as a theory in philosophy and has adopted a rational approach to it because philosophy by its nature is a rational activity. On the educational note the paper examined how rational empiricism could be a useful philosophical foundation for educational
\end{abstract}

practice by postulating a philosophical principle for facilitating knowledge acquisition.

\section{Introduction}

It is often said that experience is the best teacher, or that man learn from experience. This saying about men and experience provides a starting point for an examination of the concept of experience and its importance in man's ability to learn and if necessary to teach. Such an examination into the nature of experience can be considered relevant to education in as much as it is linked with teaching and learning. The practice of education borders on these two activities. The study employs the approach of philosophical analysis to analyse the concept of experience and its place in knowledge acquisition. A major goal of education is the acquisition and dissemination of knowledge. This is not to overlook other outcomes of the educational process such as development of skills, attitudes and personality, among others. Notwithstanding the various facets to self development that may arise from an educational system, one salient point to bear in mind is that knowledge is a principal stock in trade for educators. The educator makes use of knowledge to impart further knowledge. The theory and practice of education involves knowledge of man and his environment since it is man that carries out the planning and implementation of education and it is for the sake of man that education takes place. This paper is set basically to examine the empiricist concept of knowledge and its philosophical relevance to education. 


\section{Appraisal and analysis of knowledge}

The concept of knowledge could be given various interpretations, while one could interprete knowledge to mean recognition as for instance when one claims to know a person whom he had met before, one can also interprete knowledge to mean discovery, as for instance when one claims to know a person's secrets. Also one can interpret knowledge as experience of truth of facts or skills. Those are among possible interpretations. In any discussion of knowledge three things come to mind. These are; the knower (the person that possess knowledge), the phenomenon known and the assurance that the knower actually knows. Many scholars have based their theories of knowledge on these three elements. When a person shows a desire to know, there develops in him an inner curiosity over a particular phenomenon. The phenomenon constitutes his object of inquiry, and such object of enquiry often comes about through sensory or cognitive contact with things in the world. The inquirer claims to know when he experiences a feeling of certainty about the reality of his object of inquiry. This is a condition of mind that knowledge entails. Plato explains knowledge as "justified true belief" [1]. The terms; belief, truth and justification are considered paramount to the understanding of knowledge. This definition admits that knowledge is essentially belief and that truth is crucial to accepting a belief as knowledge. The point of examination in this definition is the notion of 'justification'. Justification of one's belief goes beyond mere provision of evidence. The evidence must constantly justify what it stands for, because it is possible to base one's belief with regard to a phenomenon on a circumstantial evidence while such evidence does not justify the truth of the reality of such phenomenon. Bertrand Russell attests to this when he wrote: "It is very easy to give examples of true beliefs that are not knowledge. There is the man who looks at a clock which is not going, though he thinks it is, and who happens to look at it the moment when it is right, this man acquires a true belief as to the time of the day, but cannot be said to have knowledge" [2]. According to this assertion, the man acquires a true belief as to the working condition of the clock but does not possess knowledge of it. To justify a belief as knowledge therefore requires not only that the evidence for the belief must be true, but that it must be constantly true to what it stands for.
Thus, justification based on consistency of evidence for the truth of a belief is an important factor that unifies belief and truth as knowledge. A.J. Ayer also stated the criteria for knowledge as truth and certainty [3]. These two are more or less the same thing because for none idea to be true is for one to be certain of it and one is certain of anything only when one possess true idea about it. The notion of certainty therefore connotes awareness since one cannot be certain of what he is not aware of. This theory is built on Plato's theory of knowledge. A close examination of some other scholars' theory of knowledge also revolves around these criteria. Gilbert Ryle, defined knowledge on what it consists of by classifying knowledge into what he termed 'Knowledge-How' and 'Knowledge-that' [4]. This distinction is made between knowing how to do something and knowing that something is the case. The first one centers on action while the later one centers on belief or fact. Both are Concomitant in the sense that the later is stepping stone of the first. In either of the two classifications one would rightly argue that knowledge is portrayed as experience that is verified and justified in truth. This also stresses the place of experience in knowledge acquisition. One may ask how does the activity of knowing takes place? To this, Bamisaiye provided a clue for answering this question. She defined the activity of knowing as a 'cognitive encounter by a learner with an object of learning and internalization of such an encounter' [5]. This definition says that knowledge is obtained through an encounter a person makes with an object of inquiry but leaves one question; whether it is the encounter that learner (or knower) internalizes or it is the object of inquiry. It also raised an important question as to whether every cognitive encounter brings about knowledge. To these questions one would assert that every cognitive encounter exposes the mind to an object of inquiry not the activity of inquiry as such, hence not every cognitive encounter guarantees knowledge unless the truth of such encounter is internalized. Educational institutions for example, function to take learner through various cognitive encounters but not all that makes the encounters actually come to know. For example, the teacher in the classroom adopts pedagogical strategies to expose the minds of the pupils to certain objects of inquiry. This is a cognitive encounter. When he evaluates his pupils at the end of the lesson, he may discover that while some of his pupils know what they were 
taught, some do not know it even though the pupils were involved in the cognitive encounter.

\section{Analysis of knowledge as experience}

The Cartesian method of doubt provides a beginning for our comparable analysis of these concepts. In his "Meditation" Descartes expresses doubt about everything he once believed and through his method of doubt, he establishes certainty of knowledge. He warns that ordinary claim to knowledge may prove mistaken because according to him the senses cannot be trusted since they are sometimes deceptive [6]. It follows therefore that sensation on its own does not guarantee knowledge. But does it guaranty experience? We can assert that sensation brings about experience. Through sensation a person becomes aware of the existence of certain phenomena but he may not claim knowledge of them until he ascertains that the reality of what he perceives is true to what they are. Knowledge of a phenomenon therefore depends on the truth of the reality of the phenomenon. One important point to bear in mind is that knowledge and experience are features of man's intellectual contact with the world. They are interrelated terms. The Kantian understanding of the relationship between knowledge and experience is more edifying. Knowledge, for Kant begins with experience as he himself described it: "That all our knowledge begins with experience there can be no doubt... in respect of time therefore, no knowledge of ours is antecedents to experience but begins with it" [7]. Knowledge from this passage is preceded by, and generated from experience. This implies that there is no knowledge outside experience. But Kant's classification of knowledge into 'A priori' (knowledge outside experience), and 'A posteriori' (knowledge that has its source in sense experience) seems to indicate a contradiction by ascertaining knowledge outside experience. In his explanation, he takes the term 'A priori' as absolutely related to all experience. This type of knowledge could be understood as pure in the sense that there is no admixture of anything empirical in it. This provides a blend with the other term 'A posteriori' which is empirical, for he contended that time and space are too sources of knowledge form which 'a priori' and its relation forms the basis for mathematics. For anything known, there is contiguity in space and extension in time. One would deduce from these explanations that all knowledge is experience but not every experience is knowledge since not every experience is accompanied with the possession of truth of the reality of what is experienced. It is the search for the truth of experience that places the knowledge seeker on the place of the skeptic. Thus skepticism is the first experience for a knowledge seeker and such truth is realized through sensation and reason. This is to say that knowledge as experience depends on perception in its realization of truth. Thus, perception is crucial to acquisition of knowledge and experience.

\section{Research rationale}

The concept of experience has been chosen as a point of departure in this paper because of various interpretations that could be given to it. While some people may interpret experience as knowledge, which is the degree of knowledge that a person has, some may see it purely as activity of the senses, which is for instance, when you describe somebody as experiencing a fire burn. Others too may interpret the concept as a function of time, as when we talk of a person's years of experience at work. These and many more possible interpretations of experience provided a starting point for a critical examination of the concept in relation to knowledge and education. Experience as defined by the Oxford Dictionary of Current English is a 'knowledge based on personal observation or contacts'. Other dictionaries define experience either as knowledge or as a process of gaining knowledge. Each of the possible definitions makes a connection of experience with knowledge either in itself knowledge or as a process of knowledge acquisition. Experience is basically a behavioral term. Even when an experiencer engages in mental activity such an activity depicts the behavior of the time of the activity. Experience therefore is the totality of man's response to the stimulus situation. Stimulus situation can be understood in a broad sense to mean all that happens within the scope of man's awareness, since whatever attracts man's attention stimulates him to further inquiry about himself and his environment.

John Dewey defines experience as "trying to something and having the thing perceptibly do something to one in turn" [8]. This definition says nothing more on experience as a concept than assert the point that it encompasses perception and concept formation. William James identifies 
experience with consciousness and distinguishes it from conception, reasoning or thought and associates it mainly with sensation and feeling [9]. This is one-sided view of the concept of experience because sensation and feeling cannot be dissociated from their accompanying conception, reasoning or thinking during the process of acquisition of experience. It follows therefore that; conception, reasoning and thought are associates of experience too.

Experience is a behavioral term because man's response to stimuli situation is the mark of having experience. As a behavioral concept experience can be understood in terms of memory which entails the activity of thinking and remembering, among others, again all these phenomena bear upon perception and concept formation. Some philosophers construe memory as a source of experience and knowledge. This is understood in the sense that some experiences are stored in memory to generate other experience. One pertinent point to bear in mind is that the concept of memory bears upon experience and is overtly manifest in perception and concept formation, and it is these that knowledge consists of. Thus, perception is crucial to acquisition of knowledge and experience.

The verb 'perceive' from which the noun 'perception' derives, is taken from the Latin word 'perciperi' which means 'to attain awareness or understanding'. Awareness and understanding are two key terms that explain the concept of perception. Perception as an activity involves: person, who is a perceiver; the object of perception and; the process of awareness that perception entails. Perception is a behavioral phenomenon that involves primarily the use of the senses. It is either limited to sensation or it incorporates reason with sensation. Thomas Reid upholds that there are sensations, and that whenever some instance of perception occurs then some sensation is experienced. Sensations are understood by Reid as affections or feelings which exhibit in the mind while perception is always directed to something external [10]. This can be faulted on the fact that sensation cannot be distinguished from perception in this way. We need to bear in mind that both sensation and perception express conditions of mind with regards external object. The first make a representation of object in the mind while the later interprets the representations. Thus, it is the description of sensation that leads to perception. The perception built on sensation arises in judgment based on sensation of the object in relation to the perceiver. This shows that sensation is causally related to perception.

\section{Perception as related to knowledge and experience}

In view of the possible interpretations of knowledge and experience we decide to examine the concepts from the empiricist's perceptive and have therefore focused on experience as perception since empiricists establish a relationship between knowledge and experience through perception. Perception as we shall see comprises of sensation and reason. As we shall see sensation and reason constitute the core of educational activity which takes place in the process of teaching and learning. Perception is an experiential phenomenon based primarily on sensation. It is a 'process' and 'product' word. As a process word, it is instrumental to knowledge acquisition. While as a 'product' word, it is the culmination of every sensual activity. Knowledge too is essentially experiential. Perception could be interpreted as a criterion for knowledge in the sense that it is indisputable to having experience. Knowledge and experience have their basis in it and our knowledge or experience often make reference to some perception. One would assert that perception as a 'process' would constitute a necessary first step in the process of acquisition of knowledge and experience. The second and complementary would be term as conception. For instance as child grow up through the use of language, he learns to give names to thing that constitute his perceptual data and he learns to differentiate between objects in terms of their appearances and utility and by so doing learns to know the relationship between them. This is beginning of concept formation. His conception of height, weight, length and other qualities is derived from his perception of objects that possess these qualities is derived from his perception of objects that possess these qualities. He learns to conserve such ideas and later on use them as basis for other ideas. The interrelationship of perception and concept formation would be understood through a brief analysis of man's cognitive development, using Piaget's analysis of the child's intellectual development for a guide [11]. From birth, a child is aware of his own existence trough sensation and gradually begins to appreciate the existence of people and objects around him. This 
is overtly the beginning of his perceptual experience. This experience is primitive and subjective. When the child begins to develop, he learns to differentiate between various existents. In this way he learns to acquire knowledge of these various existents. This knowledge is mainly subjective. As the child further develops between the ages of two to seven years, he learns the language and culture of the people around him. Through the use of language he learns to give names to things that constitute his perceptual data and he learns to differentiate between objects in terms of their appearances and utility and by so doing learns to know the relationship between them. This is the beginning of concept formation. At the ages of seven to twelve, according to Piaget, the child develops capability for logical thinking. He learns to organize within himself his perceptual data in order of importance and in relation to which concept he takes as the mode of operation. Later as the child continues to grow, he gradually learns to develop abstract thinking on concepts such as space, colour, time and others. These are actually metaphysical realities in the sense that conceptual knowledge of them progresses from thinking on perceptual data in which they subsist to abstract thinking on the concepts themselves. For example, the concept of weight remains what it is irrespective of what is weighted since a weight consistently remains a property of gravitation of an object especially towards the centre of the earth. Both perception and conception are inclusive in the process of knowledge acquisition. That is to say, all knowledge makes connections with some perception and in turn entails conception. Knowledge as experience entails perception of the knower, the phenomenon known, as well as the internalization of the truth of what is perceived.

\section{A Theory of knowledge}

At his juncture we need to consider the salient points that emerge from various theories of knowledge, experience and perception so far examined. With this point we shall proffer some theories of knowledge that would highlight the place of empiricism in any cognitive encounter since knowledge is understood and defined in terms of experience and perception and these are empirical phenomena. To begin with, let us remind ourselves with earlier theories considered. The Platonic theory that knowledge is justified true belief form a stepping stone for our theory of knowledge. The key concepts for knowledge in Plato's theory are belief, truth and justification. It is on justification of belief as truth that knowledge rests and this is our point of focus. Such justification is based on the consistency of evidences. Akin to this is the Ayerian theory that the criteria for knowledge are truth and certainty. Again the notion of certainty as a criteria for knowledge buttresses Plato's notion of justification as necessary for knowledge and both have empiricism as their foundations this is much more so of the notion of certainty in the sense that to ascertain a truth requires observation of facts. Such observation could be made externally or internally. Also Ryle's categorization of knowledge as knowledge 'of facts' and knowledge 'of skills' clearly postulates knowledge as experience since facts or skills are occurrences of human experience. From these theories one would make some assumptions that: truth and experience are components of knowledge, that verification and justification are essential to ascertaining the truth of knowledge, that knowledge is derived from the mental function of sorting the truth of experience. These assumptions form the basis of our theory of knowledge.

As postulated earlier, our working definition of knowledge is the encounter of mind in which a person becomes aware of the truth of an experience. The definition is based on these submissions: That knowledge is an encounter of the mind; that truth is a condition for knowledge; that knowledge is essentially experience. First we shall examine mind in relation to knowledge to analyze the submission that knowledge is an encounter of the mind. In functioning through the body the mind perceives from within and outside the body, under the control of the brain. Perception from outside the body requires the agency of sensory modalities and application of reason to interpret the sense data received. During perception the sense of sight for instance brings upon the mind some visual images. The mind in turn receives and interprets them to give meaning to them. In addition it retains the memory of these percepts. Similarly the auditory organ brings the sounds upon the mind. The mind again serves in the capacity of receiving, interpreting and retaining these sounds. A similar occurrence takes place through the other sensory modalities. On the other hand perception from within the body requires that the mind makes use of some internal 
sense organs located in the muscles, for instance, to bring about information on emotional condition of the perceiver to interpret the data received accordingly. For example a person who experiences a hunger and his stomach rumble, the sensation of hunger comes from within the person and the reaction of the stomach is registered in the mind which in turn interprets it as a reaction to lack of food. Also let us consider a situation in which student experiences a feeling of discomfort as a result of the anxiety about his forthcoming examinations. The sensation o0f discomfort is generated within the student and comes about as the student perceives probability of failure in the forthcoming examination. This sensation of probability of failure is received by the mind and interpreted along the lines of discomfort. So far we have established the mind as receptor and repository of knowledge. The reception and repository of knowledge can also be functionally attributed to the intellect. Apparently one may be inclined to assume that mind and intellect are the same on the ground that both of them receives and reorganizes ideas among their other cognitive functions. But the concept of mind differs from that of intellect in the sense that the first refers to the forum for reception, reorganization and preservation of ideas, while the later concerns the level of activity of these cognitive functions.

\section{Restructured theory of knowledge, experience and perception}

We would summed up our restructured theory in the following postulates: Knowledge results from the encounter of the mind on the truth of experience; knowledge requires the mind to be and doesn't exists outside the mind; truth is a necessary condition for knowledge and it is attained through perception; experience is the essence of knowledge and is attained through perception; perception is the core of experience and, like experience, it is a 'process' and 'product' word; perception entails sensation and reason. These postulates reflect the empirical nature of knowledge and they inevitably bind knowledge acquisition with experience. They also bind the two dimensional nature of empirical thought, viz; the sensual and rational. This paper focuses on the rational dimension of empiricism in contradistinction to the sensual dimension that has been emphasized by empirical thinkers over the years.
One would believe that every school subject requires the use of reason to teach and learn. Such reasoning is based on date received through empirical or rational means. For learning of these subjects to facilitate self and technological developments much would depend on the use of sensation and reason to teach and learn them. This emphasizes the place of rational empiricism in education. At this juncture, we need to examine the philosophical relevance of our restructured theory to the practice of education.

\section{Teaching-learning and perception sharing}

It has earlier been established that knowledge and experience entails perception. Again, teaching as an experiential activity has knowledge as its basis. One would then hold that teaching, to begin with, has its central focus on development of perceptual abilities and skills. When a teacher engages in the activity of teaching he applies his sense organs and reason to perceive certain phenomena and share his perceptions of these phenomena with his learners. His teaching strategy involves receiving some perceptual data and at the same time communicating these percepts to the learners, and also provide useful guides for learners to internalize them and use the percepts to generate further perceptions. Teaching as one would say, is not one sided affair going on from the teacher to the learner. It may not be likened to filling the learners' intellects with ideas as one would fill a jar with water. Rather it calls for a simultaneous involvement of the teacher and the learner in the exchange of the stimulation of perceptual growth. But there could be variations in the perception of the teacher and the learner. This would border on the level of understanding of each of them and it depends on the diversity of thinking engaged by the two parties. For example, it is possible for the learner to be carried away to some distractions coming from the environment and make different perceptions of some phenomena other than those intended by the teaching. It is also possible for the learner to perceive the object of teaching differently from the teacher

One central point to bear is that both the teacher and the learner in any teaching and learning situation engage in sharing of perception. It is believed that they either share a similarity or dissimilarity of perceptions. They share a similarity of perception when both the teacher and 
the learner perceive in the same way. They share dissimilarity of perceptions when the teacher and the learner perceive the same phenomena differently. Such similarities or differences in perception could be at various levels. For example, imagine a teacher at an elementary school teaching his pupils who a soldier is. On his own the teacher perceives a soldier as a member of the armed forces whose function is to protect the integrity of the nation. In trying to share his perceptions he makes use of stories, pictures and illustrations to teach his pupils. Some of his pupils may share his views that a soldier is a defender of the nation's interest and integrity while it is possible for some to centralize their perception of a soldier on the notion that he belongs to the armed forces and therefore see him as a treat to the common man. It is also possible for some pupils to perceive a soldier as a candidate for coup plotting and political posts in the country, especially in the African countries. Such perception could be so influenced if the government of the country is controlled by the military. These perceptions would inevitably influence the perceiver's ideas about soldiers and attitude to the military in general. One could see that it is possible for various perceptions to emanate from the same teaching. These perceptions may not always be intended by the teacher. This therefore emphasises the need for a principle of teaching that would guide the perception of learners and ensure perception sharing between the teacher and the learner.

\section{The relevance of a rational empiricist's theory to education}

It is believed that no single method of teaching may be considered must appropriate for teaching and learning. Much depends on the nature of subjects and subject matters among other factors. While some subject could be better taught using a particular method other subjects may require a combination of methods for effective teaching and learning. In terms of perception sharing, the problem solving method would create a better forum for sharing perception between the teacher and the learner in the sense that both of them reason together to identify problems and seek solution to these problems. Other methods of teaching, like lecture, discussion and demonstration methods, would exhibit some degrees of proneness to perception sharing.
Whatever method of teaching adopted, teaching and learning centres on sharing of perception between the teacher and the learner. This emphasis the need for a principle of teaching that would lay emphasis on perception sharing as a key factor to teaching and learning. This principle should not be understood as interchangeable with method, plan or structure of teaching. Rather, it should be conceived as a philosophical principle for teaching. The focus is therefore on organization of thinking and experience for sharing of perception between the teacher and the learner, particularly in the classroom situation. The principle would advocate a democratic approach to teaching and learning since it would call for a teacher and learner perceiving together. The teacher's role consists mainly in introducing sensual stimuli to the learners and coordinating perceptions to make meaning out of them. By reasoning together on these perceptions he may induce them to further perception, which may be externally or internally made. Such perceptions would embrace the application of knowledge acquired from the lesson to daily living. This is hoped would foster selfawareness a basis for self development and would enhance knowledge of the environment as basis for technological development. The use of sensation and reason to teach would therefore be the constant feature of this principle I teaching. This should reflect in the statement of lesson objectives as well as in the method and evaluation of teaching and learning. This would be based on the philosophical assumption that teaching and learning particularly within a classroom situation entail sharing of perception between the teacher and the learner. The sharing of perception is both empirical and rational since perception has empirical and rational facets. Any teaching approach that would facilitate effective sharing of perception would necessarily be philosophical since philosophy is a rational activity that involves the use of sensation and reason to do.

\section{Conclusion and implications}

The paper was two dimensional in scope. Firstly, it seeks to explore the epistemological theory of empiricism and incorporates in it a rational dimension, because formal teaching and learning have both empirical and rational facets. Secondly, the paper examines the relevance of this theory of knowledge to educational system. It 
submitted that empiricism and rationalism are not diametrically opposed theories of knowledge; both theories can be synthesized in the sense that experience cannot be a source of knowledge unless it is accompanied by the use of reason neither can reason alone be a source of knowledge unless it is based on data received through sense experience. This paper is on both philosophy and education. On the philosophical note it has examined empiricism as a theory in philosophy and has adopted rational approach to it because philosophy by its nature is rational activity. On the educational note the paper examined how rational empiricism could be a useful philosophical foundation for educational theory and practice.

Contemporary education places emphasis on technological as well as self development. These aspirations are believed to be attainable through the study of school subjects since these subjects represent various aspects of knowledge. Such a study largely takes place formally through teaching and learning in a classroom setting. It appears that since great emphasis are placed on self and technological development as desired outcomes of education; present day education focuses on both rational and empirical knowledge. But in as much as science and technology are essentially for man and his development in the world, the empirical knowledge derived from the sciences cannot be under estimated, but such knowledge would necessarily entail rationality, since man needs to be rational in order to function meaningfully in the world. Self development and techno logical development among other forms of development are achievable through the application of lesson experiences to daily and techno logical living. The under laying factor for such application is the development of perceptual abilities. This is said to be achieved through a philosophical principle of teaching which would teach learners to think analytically upon information acquired and hoe to drive general knowledge from the particular knowledge, within the classroom, through inductive or deductive reasoning. In general this paper has focused on rational dimension of empiricism to emphasize the place of reason in experience and consequently in knowledge.

\section{References}

[1] Plato, Corn ford F.M., (trans.), The Republic, University Press, Oxford, 1974.
[2] Russell, B., Human Knowledge: Its Scope and Limits, Allen and Unwin, London, 1948.

[3] Ayer A.J., The problem of knowledge, Harmond Sworth, Penguin Books, London, 1956.

[4] Ryle G., The Concept of Mind, Harmond Sworth, Penguin Books, London, 1949.

[5] Bamisaiye R.A., Practical Approach to Philosophy of Education, A.M.D. publishers, Ibadan, 1989.

[6] Descartes, R., in E. Haldane and G.R.T., Ross, (trans.), The Philosophical Works of Descartes, Vol. I, Cambridge University, London, 1979.

[7] Kant I., Norman Kemp Smith (trans.), Critique of Pure Reason, Macmillan, London, 1929.

[8] Dewey J., Democracy and Education, Free Press, New York, 1916.

[9] Reid T., Sir William Hamiltin, (ed.), Inquiry into the Human Mind, in the works of Thomas Reid, vol. $1,6^{\text {th }}$ ed., Machachlan and Stewart, Edingburg 1963.

[10] James W., in R.M. Hutchins (ed), The Great Ideas: A Synoptic of Great Books of the Western World, University Press, Chicago, 1952.

[11] Piaget, J., The origins of Intelligence in Children, University Press, New York, 1952. 